\title{
Shaping the future of liver surgery
}

\section{Implementation of experimental insights into liver regeneration}

\author{
D. Pereyra · P. Starlinger (D)
}

Received: 9 January 2018 / Accepted: 7 February 2018 / Published online: 6 March 2018

(C) The Author(s) 2018. This article is an open access publication.

\begin{abstract}
Summary
Background While liver surgery has become a safe and feasible operation technique, the incidence of postoperative liver dysfunction still remains a central problem. Approximately $10 \%$ of patients undergoing liver resection were shown to develop liver dysfunction, which is associated with an increased risk of morbidity and mortality. Yet, to date there is no effective treatment option for postoperative liver dysfunction available. The development of postoperative liver dysfunction was linked to a disruption in the liver's potential to regenerate. Thus, it is importance to elucidate the underlying mechanisms of liver regeneration and to find potential therapeutic targets for the treatment of patients with postoperative liver dysfunction.

Methods A review of the literature was carried out. Results We report on potential future interventions for improvement of liver regeneration after surgical resection. Moreover, we evaluate the benefits and drawbacks of hepatic progenitor cell therapy and hematopoietic stem cell therapy. However, the most significant improvement seems to come from molecular targets. Indeed, von Willebrand factor and its pharmacologic manipulation are among the most promising therapeutic targets to date. Furthermore, using the example of platelet-based therapy, we stress the potentially adverse effects of treatments for postoperative liver dysfunction.

Conclusion The present review reports on the newest advances in the field of regenerative science, but also underlines the need for more research in the field of postoperative liver regeneration, especially in regard to translational studies.
\end{abstract}

D. Pereyra $\cdot$ P. Starlinger, MD, $\mathrm{PhD}(\bowtie)$

Department of Surgery, General Hospital, Medical University of Vienna, Währinger Gürtel 18-20, 1090 Vienna, Austria patrick.starlinger@meduniwien.ac.at
Keywords Postoperative Outcome - Liver Dysfunction - Therapeutic Approaches · Hepatic Progenitor Cells · Von Willebrand Factor
Abbreviations
HPC Hepatic progenitor cell
HSC Hematopoietic stem cells
IP-5HT Intra-platelet serotonin
LD Liver dysfunction
vWF-Ag von Willebrand factor antigen

\section{Introduction}

Today, liver resection represents a safe and feasible therapeutic option for the treatment of malignant and benign liver tumors $[1,2]$. This is due to a continuous refinement of surgical strategies, starting from a simple left lobe resection in 1888 and evolving into an adjustable procedure with a high degree of personalization to the patients' needs [3]. The former limitations of liver surgery, namely, bleeding at the site of resection, bilobar tumor growth, and multiple metastasis within the liver, could be overcome, which makes major resection of up to $75 \%$ of the livers initial volume a feasible and safe operation $[4,5]$. Indeed, postoperative mortality is reported to affect no more than $2-8 \%$ of patients undergoing liver resection, with the latter percentage referring to high-risk patients who require complex resections [6-9]. Of note, this is also due to advances in perioperative management of patients undergoing liver resection. In addition, the preoperative optimization of patients needing extensive liver resection has improved, with the most prominent example being preoperative portal vein embolization [10]. This technique allows for major resection also in patients with an initial future liver remnant of less than $25 \%$, as it triggers regeneration in the healthy liver parenchyma. 
Fig. 1 Repeated liver resections are possible due to well-functioning liver regeneration. a Computer tomography scan of a patient with recurrence of metastatic disease in the liver after a precedent liver resection. b Still, potentially curative liver resection could be performed, as the patient's liver fully regenerated in volume and function
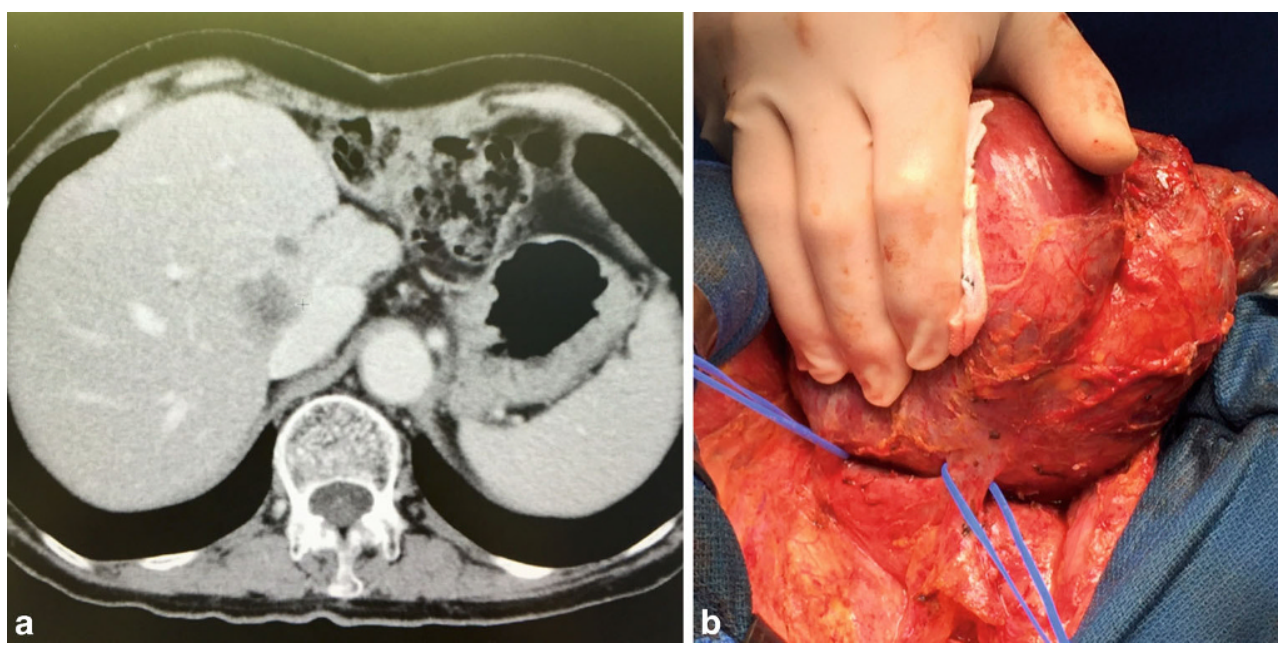

While mortality rates in this specific patient cohort are within acceptable ranges, postoperative morbidity and prolonged hospitalization, including the need for intensive care unit management and specific interventions, still remain an important concern. According to recent literature, the incidence of postoperative morbidity remains stable at $30-50 \%$ [6, 9]. Interestingly, postoperative complications have been associated with the development of liver dysfunction (LD) and delayed hepatic regeneration [11]. Indeed, a well-functioning liver regeneration after resection is believed to be the central determinant of clinical outcome [12]. Further, a well-functioning liver regeneration allows for multiple consecutive resections if needed (Fig. 1). However, if the regenerative capacity is impaired and a patient develops postoperative $\mathrm{LD}$, the clinical consequences are inevitable because to date no therapeutic approach to support postoperative liver regeneration has been identified. The fact that more than $65 \%$ of patients with postoperative LD will develop major complications highlights the need for adequate treatment options to support postoperative liver regeneration [13]. In the present review, we aim to present an overview of the most promising experimental data regarding potential therapeutic targets to support liver regeneration in patients suffering from postoperative LD.

\section{Hepatic progenitor cells and cellular therapy}

The liver consists of a variety of different cell types that display a high degree of interaction and niche dependency. Beside the main parenchymal cells, which are hepatocytes, liver-specific endothelial cells, cholangiocytes, hepatic stellate cells, and stationary macrophages (i. e., Kupffer cells) are the most frequent cell types in the liver [14]. These cells all show a high level of differentiation and specialization, which is also visible when looking at the different functions they need to fulfil. Recently, oval cells have been described as a potential hepatic progenitor cell (HPC) niche [15]. Indeed, this cell type was shown to have the ability to give rise to both hepatocytes and cholangiocytes, which led to the hypothesis that oval cells might be relevant for liver regeneration after tissue damage. Moreover, inducible progenitors were shown to be crucial for liver regeneration, and inhibition of their activation in a mouse model led to impaired liver regeneration after partial hepatectomy [16]. Thus, activation of HPCs and enforcement of differentiation to mature hepatocytes might be a potential therapeutic target for induction of liver regeneration. EspañolSuñer et al. were able to show that in vivo activation of oval cells can be performed via the $\mathrm{PGI}_{2}$ analogue iloprost [17]. Although the arising hepatocytes showed a typical behavior and were able to proliferate upon activating stimuli in vivo, these cells only contributed to $2.45 \%$ of the total hepatocytes. Further, EspañolSuñer and coworkers did not observe a massive increase in oval cell activation after partial hepatectomy in mice.

Interestingly, HPCs were found to be regulated by, if not even derived from, hematopoietic stem cells (HSC). These cells share a large panel of surface markers [18]. Furthermore, Y chromosomes were detected in female patients' hepatocytes after bone marrow transplantation from a male donor [19]. Thus, a plethora of experimental studies addressed the question of whether cellular therapy via HSCs might contribute to liver regeneration in different models [20]. In conclusion, the studies provide diverging results: While HSCs seemed to improve the outcome of mice after liver damage, this improvement could not consistently be traced back to the engraftment of HSCs [21]. In some studies, an engraftment was only observed for $4 \%$ of transplanted HSCs. Nevertheless, a compensatory proliferation of hepatocytes took place in mice treated with HSCs. Accordingly, the beneficial effects of HSC therapy were thought to be either dependent on their ability to scavenge and neutralize reactive oxygen species or due to paracrine effects on hepatocytes [22, 23]. 


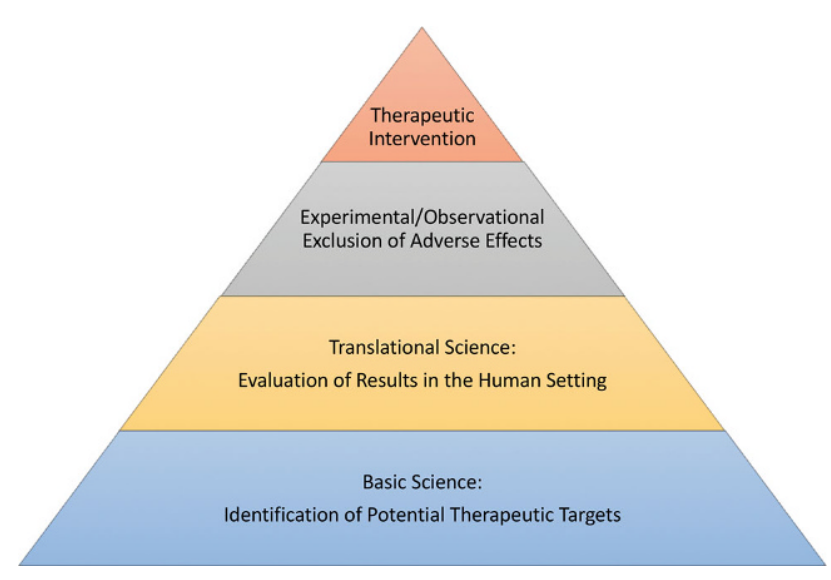

Fig. 2 Scheme of research construction in the field of liver regeneration. While basic science is clearly the basis of good research in liver regeneration, as it is vital for identification of potential therapeutic targets, translational research, comprising validation of basic research results and evaluation in the human setting, is of central importance. However, potential interfering factors as well as of potentially adverse effects need to be excluded before an evaluated target can be considered trustworthy for any kind of therapeutic intervention

Taken together, both HPCs and HSCs might have a beneficial effect on liver regeneration. However, the available data are not conclusive yet and translational data as well as prospective human trials are needed to clarify the clinical applicability of this kind of cellular therapy.

\section{Molecular targets - von Willebrand factor}

In the past few years, molecular targets became more innovative in the field of liver regeneration. This might be due to the increased interest in pathophysiologic processes taking place during the complex process of liver regeneration. However, while there are abundant data on rodent models and in vitro experiments, only few translational data have been obtained to date. In this context, we recently published a translational study focusing on von Willebrand factor antigen (vWF-Ag) during postoperative liver regeneration in humans [24]. VWF-Ag is known for its role in primary hemostasis, where it facilitates the accumulation of platelets and their binding to the sub-endothelial matrix [25]. It is stored both in granules of platelets and endothelial cells and can be released upon stimulation. Previously, vWF-Ag was proposed as a marker for portal hypertension and cirrhosis [26]. However, the role of vWF-Ag in patients undergoing liver resection has not been addressed before. While a large clinical study showed that patients with high preoperative levels of vWF-Ag had a significantly increased risk for development of postoperative LD, complications, and even mortality, we aimed to provide more insight into the pathophysiological involvement of vWF-Ag in liver regeneration. Interestingly, Kirschbaum et al. recently published experimental data on the role of
vWF-Ag during liver regeneration in mice [27]. They showed the central importance of vWF-Ag-dependent platelet accumulation especially during the early period after induction of liver regeneration. Indeed, the significance of platelets and platelet stored factors for a well-functioning liver regeneration has previously been shown by our group as well as by other researchers $[12,28,29]$. Thus, we took a closer look at vWF-Ag secretion during the early phase of liver regeneration (i.e., the first $2 \mathrm{~h}$ after portal vein ligation) in the human setting. Astonishingly, our results precisely followed the experimental data by Kirschbaum et al. We were able to validate previous reports on platelet accumulation within the regenerating liver. Interestingly, we also observed an increase in vWF-Ag within no more than $2 \mathrm{~h}$ of induction of liver regeneration. Most importantly, this initial increase was only seen in patients who did not develop LD in the postoperative time course, while patients with LD were not able to substantially secrete vWF-Ag in the early phase of liver regeneration. This led to the hypothesis that an initial burst in vWF-Ag might be relevant for induction of platelet-mediated liver regeneration.

Overall, this study provides an example of how therapeutic targets in the field of liver regeneration can be identified (for a summary, refer to Fig. 2). Thinking one step further, these data would suggest a beneficial effect of pharmacologic manipulation of vWFAg secretion. Indeed, drugs inducing this effect, such as vasopressin analogues, are already part of clinical routine. Moreover, a study investigating the use of terlipressin in patients undergoing major liver resection is currently being conducted (ClinicalTrials.gov Identifier: NCT01921985). Thus, this intervention might be the first treatment option for patients suffering from postoperative LD and might concomitantly improve the overall outcome of patients undergoing liver resection.

\section{Drawbacks from treatments}

While several different targets to treat patients suffering from postoperative LD are being investigated, not all of them will ultimately find their way into clinical practice. This can either be due to a reduced effectiveness in the human setting, as might be the case for HPC/HSC-based therapy, or that potential adverse effects of the respective treatment need to be investigated. Indeed, we and others previously hypothesized a potential positive effect of platelet-based therapy on the outcome of liver regeneration $[12,28,29]$. Specifically, within a previous study we showed that patients with low preoperative levels of intra-platelet serotonin (IP-5HT) prior to the operation have a higher risk for development of postoperative LD [30]. Thus, a pharmacological elevation of IP-5HT seemed to be a reasonable treatment option in patients undergoing liver resection. However, 5HT was also proposed as a proproliferative molecule for various malignant diseases 
Table 1 Summary of the results

\begin{tabular}{|c|c|c|}
\hline Section & Examples & Results \\
\hline Cell-based therapy & $\begin{array}{l}\text { Hepatic progenitor cells } \\
\text { Hematopoietic stem cells }\end{array}$ & $\begin{array}{l}\text { Good results in experimental models } \\
\text { Clinical application needs to be evaluated }\end{array}$ \\
\hline Molecular targets & von Willebrand factor & $\begin{array}{l}\text { Experimental evaluation showed good results } \\
\text { Translational data available } \\
\text { Pharmacologic intervention in humans currently under investigation }\end{array}$ \\
\hline Drawbacks & Platelets/serotonin & $\begin{array}{l}\text { Central for liver regeneration and thus a potential target for improvement of liver regeneration } \\
\text { However, also pro-proliferative for malignant cells and an association with early disease recurrence was } \\
\text { shown }\end{array}$ \\
\hline
\end{tabular}

including all main tumor entities of the liver [31-34]. Hence, we conducted a study with the aim to elucidate the influence of IP-5HT on the oncological outcome of patients undergoing liver resection [35]. Strikingly, patients with high preoperative levels of IP-5HT were found to suffer more frequently from early tumor recurrence within 1 year postoperatively. This study put a huge caveat on platelet-based therapy. The initially considered pharmacological manipulation might induce adverse effects and a potential intervention has to be investigated with caution. Likewise, not only 5HT, but also other platelet-contained factors were shown to interact with malignant cells and metastasis [36]. Further, these data question the beneficial effect of a proliferation-based approach for improvement of postoperative liver regeneration, as induction of proliferation in hepatocytes most likely also induces proliferation in remaining micro-metastases and circulating tumor cells.

\section{Conclusion}

Liver regeneration is a highly complex process. Yet, its understanding is of pivotal importance to improve the outcome of patients undergoing liver resection. While a multitude of potential therapeutic targets were established in the past (most important results are summarized in Table 1), only few have the potential to ultimately act as a promising therapy for patients suffering from postoperative LD. Hence, more research, especially in the translational field, is imperatively needed. However, future research should not focus exclusively on basic science, as artificial models often neglect important aspects of the multifactorial process of liver regeneration and cancer and thus might overestimate certain results.

Funding Open access funding provided by Medical University of Vienna.

Conflict of interest D. Pereyra and P. Starlinger declare that they have no competing interests.

Open Access This article is distributed under the terms of the Creative Commons Attribution 4.0 International License (http://creativecommons.org/licenses/by/4.0/), which permits unrestricted use, distribution, and reproduction in any medium, provided you give appropriate credit to the original author(s) and the source, provide a link to the Creative Commons license, and indicate if changes were made.

\section{References}

1. Fan ST, Lo CM, Liu CL, Lam CM, Yuen WK, Yeung C, Wong J. Hepatectomy for hepatocellular carcinoma: toward zero hospital deaths. Ann Surg. 1999;229:322-30.

2. Belghiti J, Hiramatsu K, Benoist S, Massault P, Sauvanet A, Farges O. Seven hundred forty-seven hepatectomies in the 1990s: an update to evaluate the actual riskofliver resection. JAm Coll Surg. 2000;191:38-46.

3. Jarnagin WR, Gonen M, Fong Y, DeMatteo RP, Ben-Porat L, Little S, Corvera C, et al. Improvement in perioperative outcome after hepatic resection: analysis of 1,803 consecutive cases over the past decade. Ann Surg. 2002;236:397-406. discussion 406-397.

4. Collins D, Chua H. Contemporary surgical management of synchronous colorectal liver metastases. F1000Res. 2017;6:598.

5. Shoup M, Gonen M, D'Angelica M, Jarnagin WR, DeMatteo RP, Schwartz LH, Tuorto S, et al. Volumetric analysis predicts hepatic dysfunction in patients undergoing major liver resection. J Gastrointest Surg. 2003;7:325-30.

6. Shubert CR, Habermann EB, Truty MJ, Thomsen KM, Kendrick ML, Nagorney DM. Defining perioperative risk after hepatectomy based on diagnosis and extent of resection. J Gastrointest Surg. 2014;18:1917-28.

7. Booth CM, Nanji S, Wei X, Mackillop WJ. Management and outcome of colorectal cancer liver metastases in elderly patients: a population-based study. JAMA Oncol. 2015;1:1111-9.

8. Gilg S, Sparrelid E, Isaksson B, Lundell L, Nowak G, Stromberg C. Mortality-related risk factors and long-term survival after 4460liver resections in Sweden-a populationbased study. Langenbecks Arch Surg. 2017;402:105-13.

9. ShubertCR, Habermann EB, BergquistJR, Thiels CA, Thomsen KM, Kremers WK, Kendrick ML, et al. A NSQIP review of major morbidity and mortality of synchronous liver resection for colorectal metastasis stratified by extent of liver resection and type of Colorectal resection. J Gastrointest Surg. 2015;19:1982-94.

10. Kwon YJ, Lee KG, Choi D. Clinical implications of advances in liver regeneration. Clin Mol Hepatol. 2015;21:7-13.

11. RahbariNN, Garden OJ, Padbury R, Brooke-Smith M, Crawford M, Adam R, Koch M, et al. Posthepatectomy liver failure: a definition and grading by the International Study Group of Liver Surgery (ISGLS). Surgery. 2011;149:713-24.

12. Lesurtel M, Graf R, Aleil B, Walther DJ, Tian Y, Jochum W, Gachet C, et al. Platelet-derived serotonin mediates liver regeneration. Science. 2006;312:104-7.

13. Skrzypczyk C, Truant S, Duhamel A, Langlois C, Boleslawski E, Koriche D, Hebbar M, et al. Relevance of the ISGLS definition of posthepatectomy liver failure in early prediction of poor outcome after liver resection: study on 680 hepatectomies. Ann Surg. 2014;260:865-70. discussion 870 . 
14. Diehl AM, Chute J. Underlying potential: cellular and molecular determinants of adult liver repair. J Clin Invest. 2013;123:1858-60.

15. Spee B, Carpino G, Schotanus BA, Katoonizadeh A, Vander Borght S, Gaudio E, Roskams T. Characterisation of the liver progenitor cell niche in liver diseases: potential involvement ofWnt and Notch signalling. Gut. 2010;59:247-57.

16. Karaca G, Swiderska-Syn M, Xie G, Syn WK, Kruger L, Machado MV, Garman K, et al. TWEAK/Fn14 signaling is required for liver regeneration after partial hepatectomy in mice. PLoS ONE. 2014;9:e83987.

17. Espanol-Suner R, Carpentier R, Van Hul N, Legry V, Achouri Y, Cordi S, Jacquemin P, et al. Liver progenitor cells yield functional hepatocytes in response to chronic liver injury in mice. Gastroenterology. 2012;143(e1567):1564-1575.e7.

18. Petersen BE, Grossbard B, Hatch H, Pi L, Deng J, Scott EW. Mouse A6-positive hepatic oval cells also express several hematopoietic stem cell markers. Hepatology. 2003;37:632-40.

19. Alison MR, Poulsom R, Jeffery R, Dhillon AP, QuagliaA, Jacob J, Novelli M, et al. Hepatocytes from non-hepatic adult stem cells. Nature. 2000;406:257.

20. Katoonizadeh A, Poustchi H, Malekzadeh R. Hepatic progenitor cells in liver regeneration: current advances and clinical perspectives. Liver Int. 2014;34:1464-72.

21. Vassilopoulos G, Wang PR, Russell DW. Transplanted bone marrow regenerates liver by cell fusion. Nature. 2003;422:901-4.

22. Parekkadan B, van Poll D, Megeed Z, Kobayashi N, Tilles AW, Berthiaume F, Yarmush ML. Immunomodulation of activated hepatic stellate cells by mesenchymal stem cells. Biochem Biophys Res Commun. 2007;363:247-52.

23. Kuo TK, Hung SP, Chuang CH, Chen CT, Shih YR, Fang SC, Yang VW, et al. Stem cell therapy for liver disease: parameters governing the success of using bonemarrowmesenchymal stem cells. Gastroenterology. 2008;134:2111-2121, 2121.e1-3.

24. Starlinger P, Pereyra D, Haegele S, Braeuer P, Oehlberger L, Primavesi F, Kohler A, et al. Perioperative von Willebrand factor dynamics are associated with liver regeneration and predict outcome after liver resection. Hepatology. 2017; https://doi.org/10.1002/hep.29651.

25. Kanaji S, Fahs SA, Shi Q, Haberichter SL, Montgomery RR. Contribution of platelet vs. endothelial VWF to platelet adhesion and hemostasis. J Thromb Haemost. 2012;10:1646-52.
26. La Mura V, Reverter JC, Flores-Arroyo A, Raffa S, Reverter E, Seijo S, Abraldes JG, et al. Von Willebrand factor levels predict clinical outcome in patients with cirrhosis and portal hypertension. Gut. 2011;60:1133-8.

27. Kirschbaum M, Jenne CN, Veldhuis ZJ, Sjollema KA, Lenting PJ, Giepmans BNG, Porte RJ, et al. Transient von Willebrand factor-mediated platelet influx stimulates liver regeneration after partial hepatectomy in mice. Liver Int. 2017:37:1731-7.

28. Starlinger P, Alidzanovic L, Schauer D, Brugger P, Sommerfeldt S, Kuehrer I, Schoppmann SF, et al. Plateletstored angiogenesis factors: clinical monitoring is prone to artifacts. Dis Markers. 2011;31:55-65.

29. Starlinger P, Assinger A. Importance of platelet-derived growth factors in liver regeneration. Expert Rev Gastroenterol Hepatol. 2016; https://doi.org/10.1586/17474124. 2016.1158100.

30. Starlinger P, Assinger A, Haegele S, Wanek D, Zikeli S, Schauer D, Birner P, et al. Evidence for serotonin as a relevant inducer of liver regeneration after liver resection in humans. Hepatology. 2014;60:257-66.

31. Alpini G, Invernizzi P, Gaudio E, Venter J, KoprivaS, Bernuzzi F, Onori P, et al. Serotonin metabolism is dysregulated in cholangiocarcinoma, which has implications for tumor growth. Cancer Res. 2008;68:9184-93.

32. Asada M, Ebihara S, Yamanda S, Niu K, Okazaki T, Sora I, Arai H. Depletion of serotonin and selective inhibition of 2B receptor suppressed tumor angiogenesis by inhibiting endothelial nitric oxide synthase and extracellular signal-regulated kinase 1/2 phosphorylation. Neoplasia. 2009;11:408-17.

33. Gurbuz N, Ashour AA, Alpay SN, Ozpolat B. Down-regulation of 5-HT1B and 5-HT1D receptors inhibits proliferation, clonogenicity and invasion of human pancreatic cancer cells. PLoS ONE. 2014;9:e105245.

34. Pang Q, Liu C, Zhang JY, Qu K, Song SD, Liu SS, Xu XS Serotonin in liver tumor: friend or foe? Hepatology. 2015;62:319.

35. Padickakudy R, Pereyra D, Offensperger F, Jonas P, Oehlberger L, Schwarz C, Haegele S, et al. Bivalent role of intra-platelet serotonin in liver regeneration and tumor recurrence in humans. JHepatol. 2017;67:1243-52.

36. Aryal B, Shimizu T, Kadono J, Furoi A, Komokata T, Inoue M, Ikeda S, et al. A Switch in the Dynamics of IntraPlatelet VEGF-A from Cancer to the Later Phase of Liver Regeneration after Partial Hepatectomy in Humans. PLoS ONE. 2016;11:e150446. 